\title{
Dynamical Mechanisms for the Recent Ozone Depletion in the Arctic Stratosphere Linked to the North Pacific Sea Surface Temperatures
}

\section{Dingzhu Hu ( $\sim$ hudz@nuist.edu.cn )}

Nanjing University of Information Science and Technology

\section{Zhaoyong Guan}

Nanjing University of Information Science and Technology

Meichen Liu

Nanjing University of Information Science and Technology

\section{Wuhu Feng}

University of Leeds

\section{Research Article}

Keywords: Dynamical Mechanisms, Ozone Depletion, Arctic Stratosphere, Sea Surface Temperatures

Posted Date: July 13th, 2021

DOI: https://doi.org/10.21203/rs.3.rs-681292/v1

License: (9) This work is licensed under a Creative Commons Attribution 4.0 International License. Read Full License

Version of Record: A version of this preprint was published at Climate Dynamics on November 29th, 2021. See the published version at https://doi.org/10.1007/s00382-021-06026-x. 


\section{Dynamical Mechanisms for the Recent Ozone Depletion in} the Arctic Stratosphere Linked to the North Pacific Sea Surface Temperatures

6

Dingzhu $\mathrm{Hu}^{1, *}$, Zhaoyong Guan ${ }^{1, *}$, Meichen Liu ${ }^{1}$, Wuhu Feng ${ }^{2,3}$

1. Key Laboratory of Meteorological Disasters of China Ministry of Education (KLME)/Joint International Research Laboratory of Climate and Environment Change (ILCEC)/Collaborative Innovation Center on Forecast and Evaluation of Meteorological Disasters (CIC-FEMD), Nanjing University of Information Science \& Technology, Nanjing 210044, China

2. National Centre for Atmospheric Science, University of Leeds, Leeds, UK 3. School of Earth and Environment, University of Leeds, Leeds, UK

*To whom correspondence should be addressed.

E-mail: hudz@nuist.edu.cn; guanzy@nuist.edu.cn 
9 and thereby protects life on earth, is expected to recover from past depletion during this

\section{Abstract}

The ozone layer, which prevents solar ultraviolet radiation from reaching the surface century due to the impact of the Montreal Protocol. However, how the ozone column over the Arctic will evolve over the next few decades is still under debate. In this study, we found that the ozone level in the Arctic stratosphere during the period of 1998-2018 exhibits a decreasing trend of $-0.12 \pm 0.07 \mathrm{ppmv}^{\text {decade }}{ }^{-1}$ from MERRA2, suggesting a continued depletion during this century. This ozone depletion is contributed by the second leading mode of North Pacific sea surface temperature anomalies (SSTAs) with one month leading and therefore dynamical in origin. The North Pacific SSTAs associated with this mode tend to result in a weakened Aleutian low, a strengthened Western Pacific pattern and a weakened Pacific-North American pattern, which impede the upward propagation of planetary wavenumber- 1 waves into the lower stratosphere.

The changes in the stratospheric wave activity tend to result in decreased ozone in the Arctic lower stratosphere through weakening the Brewer-Dobson circulation. Our findings will provide new understanding of how dynamical processes control Arctic stratospheric ozone and will help to improve prediction of how Arctic ozone will evolve in the future. 


\section{Introduction}

Stratospheric ozone, which comprises about $90 \%$ of the total amounts present in the Earth's atmosphere, is a radiatively and chemically active gas that shields the Earth from harmful solar ultraviolet radiation (WMO, 2018). In the stratosphere, ozone changes can alter the temperature and its gradient via radiative effects (Ramaswamy, 2001) and modify the circulation and wave activity via radiative-dynamical feedbacks (Hu \& Tung, 2003; Eyring et al., 2007; Hu et al., 2015). Some studies have shown that depletion of stratospheric ozone during the austral summer may result in a substantial poleward shift of the mid-latitude jet (Thompson et al., 2011), widening of the Hadley circulation (Son et al., 2010), an increase in southern hemisphere subtropical precipitation (Kang et al., 2011) and the poleward extension of the subtropical dry zones (Polvani et al., 2011). Ozone depletion in the Arctic may also affect sea-level pressure (SLP), temperature, and precipitation in most parts of the Northern Hemisphere (NH) (Calvo et al., 2015; Ivy et al., 2017).

As a result of the rapid increase in anthropogenic emissions of Ozone Depleting Substances (ODSs) through the mid-1990s (Weatherhead \& Andersen, 2006), the global averaged total ozone column showed a negative trend from the late 1970s to the late 1990s (WMO, 2007). With the observed decrease in ODSs in the atmosphere from the 1990s under the impact of the Montreal Protocol and its amendments (Chipperfield, 2015), numerical studies have shown that ozone concentrations in the upper stratosphere will recover due to the decreased ODSs (WMO, 2018). Chemistry-climate 
models predict that stratospheric ozone will recover to pre-1980 levels around 2050 and may exceed pre-1980 levels during this century (e.g., Weatherhead \& Andersen, 2006). Bednarz et al. (2016) suggested that the ozone in the NH may recover to 1980 levels by about 2030-2040.

Datasets from National Aeronautics and Space Administration and National Oceanic and Atmospheric Administration satellites show that ozone concentrations in the mid- and upper stratosphere increased slowly during 2000-2016 (Steinbrech et al., 2017). However, some studies have suggested that there was no significant trend in the concentrations of ozone in the lower stratosphere from 1984 to 2011 (Tummon et al., 2015) or from 1995 to 2013 (Cohen et al., 2018). Other studies have reported that ozone concentrations derived from merged datasets in the lower stratosphere between $40^{\circ} \mathrm{S}-$ $40^{\circ} \mathrm{N}$ after 1997 (Bourassa et al., 2014) and between $60^{\circ} \mathrm{S}-60^{\circ} \mathrm{N}$ after 1998 (e.g., Ball et al., 2018, 2020; Wargan et al., 2018) were still decreasing. Given the declining ODS concentrations, extensive research, vigorous debate and a number of papers tried to refine the results and propose potential mechanisms after the continuing decline of the ozone in the lower stratosphere in the $21^{\text {st }}$ century was first reported by Ball et al. (2018). While these studies focused on tropical and midlatitudinal ozone trends. The result on the ozone over the Arctic in the NH is still unclear. Note that there has been a significant chemical depletion of ozone during a number of Arctic winters during the past two decades (Tilmes et al., 2004; Manney et al., 2015). In particular, the magnitude of the reduction in ozone concentrations in the Arctic observed in the late winter and early spring of 2011 was comparable with that in the Antarctic (Manney et al., 2011). The 
lowest observed ozone levels in the Arctic occurred in 2020 and covered an area about three times the size of Greenland (e.g., Witze, 2020; Manney et al., 2020, Lawrence et al., 2020, Dameris et al., 2020, Innes et al., 2020, Wohltmann et al., 2020). These numerical and observational results point to two elements: the apparent negative trends over the past two decades constitute a new and intriguing result and large variability is a confounding factor in trend estimation.

Stratospheric ozone is not only affected by chemical processes related to ODSs (Rex et al., 2004), but is also modulated by SSTs via dynamical processes (e.g., Hu et al., 2014). Some studies have shown that SSTs in the North Pacific have significant impacts on the stratospheric Arctic vortex (e.g., Hu et al., 2018). Hu et al. (2018) reported that warming in the central North Pacific may lead to a strengthened stratospheric Arctic vortex during the boreal winter. Other studies have shown that the Arctic vortex is closely related to the concentrations of stratospheric ozone (e.g., Hu et al., 2015). Polar vortices in cold years would have increased polar stratospheric cloud occurrence, on the surface of which chlorine-activating heterogeneous reactions occur, further reducing the ozone (Solomon et al., 1994; Chipperfield et al., 1999; Daniel et al., 1999). The strength of the polar vortex during boreal winter is partly controlled by wave driving (Hu et al., 2018). The stronger and more variable wave driving can affect the ozone concentrations by both ozone transport (i.e., dynamical resupply) and chemical depletion (e.g., Strahan et al., 2016), i.e., stronger (weaker) wave driving is closely associated with increased (decreased) ozone by dynamical resupply and increased (decreased) ozone by reducing (increasing) ozone loss. A question therefore 
arises about whether the stratospheric ozone concentrations over the Arctic are affected by SSTs over the North Pacific and how can these SSTs affect stratospheric ozone.

To answer above questions, we use reanalysis, observational datasets and a chemical transport model to investigate the trends in ozone concentrations over the Arctic in the lower stratosphere during 1998-2018 and provide a dynamical mechanism. Our results show that the ozone has declined during this period, which can be ascribed to the second leading mode of the North Pacific SSTAs or Victoria mode, the lowfrequency variability in the North Pacific that cannot be explained by the Pacific decadal oscillation alone (Bond et al., 2003; Ding et al., 2015). The North Pacific SSTAs associated with the Victoria mode influence stratospheric ozone through reducing the planetary wavenumber-1 wave upward propagation in the extratropical stratosphere, weakening the Brewer-Dobson circulation (BDC). The recent ozone depletion in the Arctic lower stratosphere and its links to the North Pacific SSTs suggest that some potential dynamical processes also play a key role in the Arctic ozone variations, not only the ODSs controlled by the Montreal Protocol and the associated chemical processes.

\section{Data, numerical experiments and methods}

\subsection{Datasets}

The monthly mean temperature, horizontal and vertical winds, geopotential height, SLP, and ozone datasets during 1980-2018 from Modern-Era Retrospective Analysis for Research and Applications version 2 (MERRA2) are used in this study. Wargan et al. (2018) demonstrated that the ozone record from MERRA2 can be homogenized 
112 allowing reliable trend calculations. We also used the monthly mean ozone datasets

113 from Global OZone Chemistry And Related trace gas Data records for the Stratosphere

114 (GOZCARDS), partial column ozone field from Solar Backscattered Ultraviolet

115 (SBUV), Stratospheric Water and OzOne Satellite Homogenized (SWOOSH),

116 Microwave Limb Sounder (MLS). The SST data from the Extended Reconstructed Sea

117 Surface Temperature V5 was used. The description of above data sources is listed in

118 Table 1.

119 Table 1. Description of the data sources used in this study.

\begin{tabular}{cll}
\hline Datasets & \multicolumn{1}{c}{ Download websites } & \multicolumn{1}{c}{ References } \\
\hline MERRA2 & https://disc.gsfc.nasa.gov/datasets/M2IMNPASM_V5 & Gelaro et al. (2017) \\
& $.12 .4 /$ summary?keywords=merra-2 & \\
GOZCARDS & https://disc.gsfc.nasa.gov/datasets/GozSmlpO3_V1 & Froidevaux et al. (2015) \\
SBUV & https://disc.gsfc.nasa.gov/datasets/SBUV2N09L3zm_ & Kramarova et al. (2013); \\
& V1 & Bhartia et al. (2013) \\
SWOOSH & http://www.esrl.noaa.gov/csd/groups/csd8/swoosh/ & Davis et al. (2016) \\
MLS & https://disc.gsfc.nasa.gov/datasets/ML3MBO3_005/s & Schwartz et al. (2021) \\
& ummary?keywords=MLS & \\
ERSST V5 & https://www.esrl.noaa.gov/psd/data/gridded/data.noaa & Huang et al. (2017) \\
& .ersst.v5.html & \\
\hline
\end{tabular}

\subsection{Model and simulations}

TOMCAT/SLIMCAT (hereafter TOMCAT), a three dimensional (3D) chemical

123 description of chemistry for troposphere and stratosphere including heterogeneous

124 reactions on sulfate aerosols and liquid/solid polar stratospheric clouds (Chipperfield et

125 al., 2018a) as well as chemistry reactions of the oxygen, nitrogen, hydrogen, chlorine

126 and bromine families (Grooss et al., 2018). The model has identical stratospheric

127 chemistry and aerosol loading, solar flux input and surface mixing ratios of long-lived 
source gases as Chipperfield et al. (2018a).

Two experiments have been designed. The reference experiment was forced using European Centre for Medium-Range Weather Forecasts ERA-Interim reanalysis products, with a resolution of $2.8^{\circ} \times 2.8^{\circ}$ and 32 vertical levels from the surface up to $\sim 60 \mathrm{~km}$. The only difference between the reference run and sensitivity run (ODSfix) is that the ODSs after year 1995 are fixed in the sensitivity run but are time-varying in the reference run.

\subsection{Methods}

As the BDC is a Lagrangian mean circulation and is approximated by the residual mean meridional circulation of the transformed Eulerian-mean equations (Dunkerton 1978), the various processes which can influence the zonal-mean ozone can be separated into the advection of ozone by the BDC or mean ozone transport, the largescale eddy transport, and the chemical net production term (Garcia and Solomon, 1983). The zonal mean ozone tracer continuity equation in the transformed Eulerian-mean formulation in spherical geometry following Garcia and Solomon (1983), is as follows:

$$
\begin{gathered}
\frac{\partial \bar{\chi}}{\partial t}=-\frac{\bar{v}^{*}}{a} \frac{\partial \bar{\chi}}{\partial \varphi}-\bar{\omega}^{*} \frac{\partial \bar{\chi}}{\partial z}-\frac{1}{\rho_{0}} \nabla \cdot \boldsymbol{M}+\bar{S} \\
\bar{v}^{*}=\bar{v}-\frac{1}{\rho_{0}} \frac{\partial}{\partial z}\left(\rho_{0} \frac{\overline{v^{\prime} \theta^{\prime}}}{\overline{\theta_{z}}}\right) ; \quad \bar{\omega}^{*}=\bar{\omega}+\frac{1}{\operatorname{acos} \varphi} \frac{\partial}{\partial \varphi}\left(\cos \varphi \frac{\overline{v^{\prime} \theta^{\prime}}}{\overline{\theta_{z}}}\right) \\
\boldsymbol{M}^{(\varphi)}=\rho_{0}\left(\overline{v^{\prime} \chi^{\prime}}-\frac{\overline{v^{\prime} \theta^{\prime}}}{\overline{\theta_{z}}} \frac{\partial \bar{\chi}}{\partial z}\right) ; \boldsymbol{M}^{(z)}=\rho_{0}\left(\overline{\omega^{\prime} \chi}+\frac{1}{a} \frac{\overline{v^{\prime} \theta^{\prime}}}{\overline{\theta_{z}}} \frac{\partial \bar{\chi}}{\partial \varphi}\right)
\end{gathered}
$$

where $\bar{\chi}$ is the zonal mean ozone concentration, $\bar{v}^{*}$ and $\bar{\omega}^{*}$ calculated as Eq. (2) are the meridional and vertical velocities of BDC, respectively, defined by Andrews et al. (1987). $\bar{S}$ is the chemical net production of ozone. The variables $v$ and $\omega$ are the meridional and vertical winds, respectively, $\theta$ is the potential temperature, $a$ is the 
150

151

152

153

154

155

156

157

158

159

160

161

162

163

164

165

166

167

168

169

170

171

Earth's radius, $\rho_{0}$ is air density, $t, \varphi$ and $z$ are time, latitude, and height, respectively. The overbars and primes denote the zonal mean and the departure from the zonal mean, respectively. The first and second terms on the right-hand side of Eq. (1) represent the advection of ozone by the BDC or the mean ozone transport. $\nabla \cdot \boldsymbol{M}$ is the divergence of the eddy flux vector $\boldsymbol{M}$. The components of $\boldsymbol{M}$ are defined in Eq. (3) by Garcia and Solomon (1983). The eddy flux vector represents the mass flux of ozone eddies by the wave components of the wind velocities, so the third term in Eq. (1) represents the large-scale eddy transport of ozone. The fourth term $\bar{S}$ in Eq. (1) represents the chemical net production of ozone.

The linear trends are estimated by the Sen median slope and their statistical significance is tested by the Mann-Kendall method because non-parametric methods are less sensitive to outliers.

\section{Decreasing trend in the ozone over the Arctic in the lower stratosphere}

Figure 1 shows the trends in the zonal mean ozone concentrations in March derived from MERRA2 reanalysis and reference simulation in TOMCAT/SLIMCAT (hereafter TOMCAT) during 1998-2018. Downward trends in the March zonal mean ozone mixing ratios can be seen in the Arctic lower stratosphere during the period 1998-2018 in both MERRA2 (Fig. 1a) and TOMCAT three-dimensional chemical transport model (Chipperfield, 2006) (Fig. 1b), with the largest negative trends occurring in the subpolar regions $50^{\circ}-70^{\circ} \mathrm{N}$ at $100-150 \mathrm{hPa}$. The negative trends during 1998-2018 from MERRA2 can also be observed during different periods with the start point of the time series shifted several years earlier or later (figure not shown). The time 
172 series of ozone averaged over $65^{\circ}-90^{\circ} \mathrm{N}$ from $100-150 \mathrm{hPa}$ (hereafter $O_{3_{-} A L S}$ ) during

$173 \quad 1998-2018$ (Fig. 1c) also shows statistically significant negative trends of $-0.12 \pm 0.07$

174 ppmv decade ${ }^{-1}$ from MERRA2 and $-0.07 \pm 0.06$ ppmv decade ${ }^{-1}$ from TOMCAT,

175 respectively. Also, the year-to-year variability of ozone in the Arctic lower stratosphere

176 from MERRA2 and TOMCAT (Fig. 1c) can be observed clearly and is highly consistent,

177 with a correlation coefficient of 0.87 , statistically significant at/above the $95 \%$

178 confidence level. Moreover, the levels of ozone from MERRA2 are highly correlated

179 with those from SWOOSH $(r=0.91)$, GOZCARDS $(r=0.82)$, and SBUV $(r=0.92)$

180 with these three correlation coefficients all statistically significant at/above the 95\%

181 confidence level. These results suggest the downward trend of ozone over the Arctic in 182 the stratosphere is reliable. 

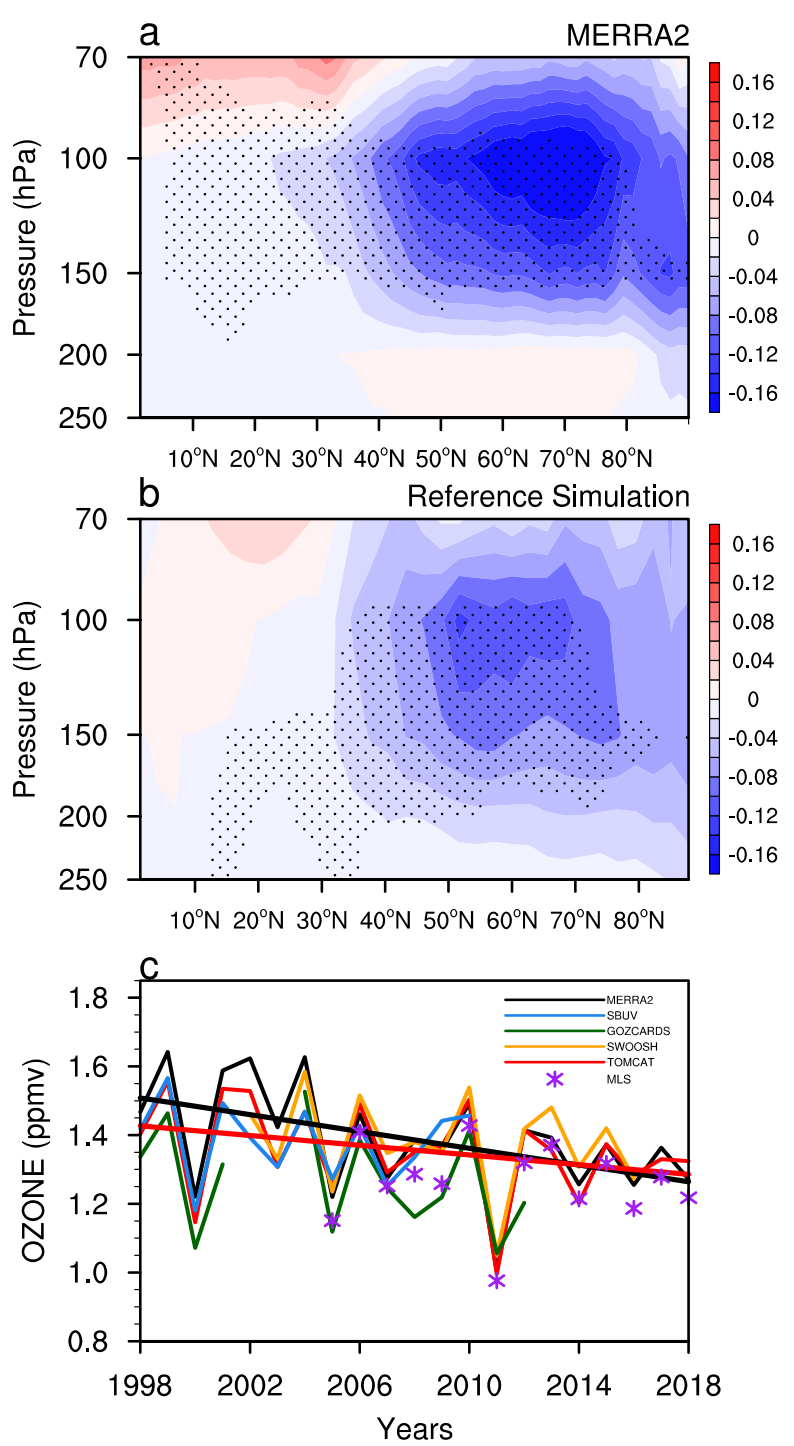

Figure 1. (a-c) Trends (units: ppmv decade ${ }^{-1}$ ) in the zonal mean ozone concentrations in March derived from (a) MERRA2 reanalysis and (b) TOMCAT simulations during $1998-2018$, and (c) time series of ozone concentrations averaged over $65^{\circ}-90^{\circ} \mathrm{N}$ and $100-150 \mathrm{hPa}$ derived from different databases in March. The black and red straight lines represent the linear trends of ozone concentrations from MERRA2 and reference run in TOMCAT/SLIMCAT, respectively. The values over the stippled regions are statistically significant at/above the $90 \%$ confidence level. 
193

194

195

196

197

198

199

200

201

202

203

204

205

206

207

208

MERRA2 and TOMCAT are also observed during the period 1980-1997, which is shown in Fig. 2. The statistically significant decreasing ozone trends at high-latitude before 1980-1997 indicate a depletion of Arctic stratospheric ozone, consistent with previous studies (WMO, 2018). However, the negative ozone trends at high-latitude in the lower stratosphere during 1980-1997 (Fig. 2) are larger than those during 19982018 (Fig. 1), which is possibly because of the decreased ODSs during the latter period (WMO, 2018). Previous studies revealed that there are statistically significant decreasing trends in the concentrations of stratospheric ozone from 1979 to mid-1990s (WMO, 2018). The ozone concentrations are expected to recover to pre-1980 levels around the middle of this century under the effects of Montreal Protocol and its Amendments (e.g., Weatherhead \& Andersen, 2006; WMO, 2018). However, the observations and simulations (Fig. 1) presented here all show a continued decreasing trend in the levels of ozone in the Arctic lower stratosphere after the 2000s, which suggests that the levels of ozone in this region have not started to recover as expected, but the downward trend after the 2000 s is slightly smaller because of the deceasing ODS levels. 


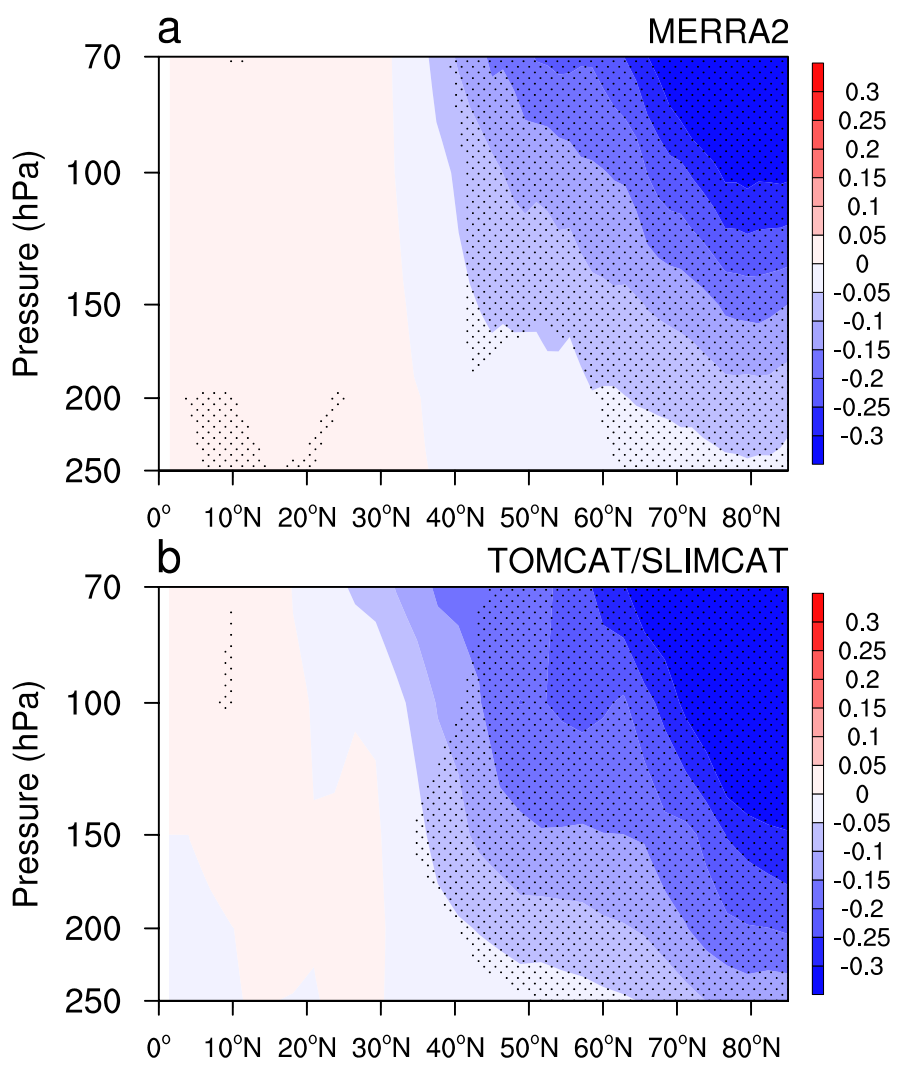

210 Figure 2. Trends (units: ppmv decade ${ }^{-1}$ ) in the ozone concentrations during 1980-1997 in March from (a) MERRA2 and (b) TOMCAT. Stippled areas are for values at/above $95 \%$ level of confidence.

To further verify the role of ODSs played in the ozone trends after the 2000 s, the sensitivity experiment in which ODSs are fixed after the 1995 has been designed. More details can be seen in Section 2.2. Figure 3 shows the trends in the zonal mean ozone concentrations in March from reference run and ODSfix run in TOMCAT during 19982018. It is clear that the trends in ozone concentration in the Arctic stratosphere in two runs are both statistically significantly negative, with smaller negative trends in reference run (Fig. 3a) but larger negative trends in ozone in ODSfix run (Fig. 3b). This smaller negative trend in ozone between the sensitivity and reference simulations in TOMCAT (Fig. 3) not only confirms the role of decreased ODSs after the 2000s, but 
223 Arctic in the stratosphere.
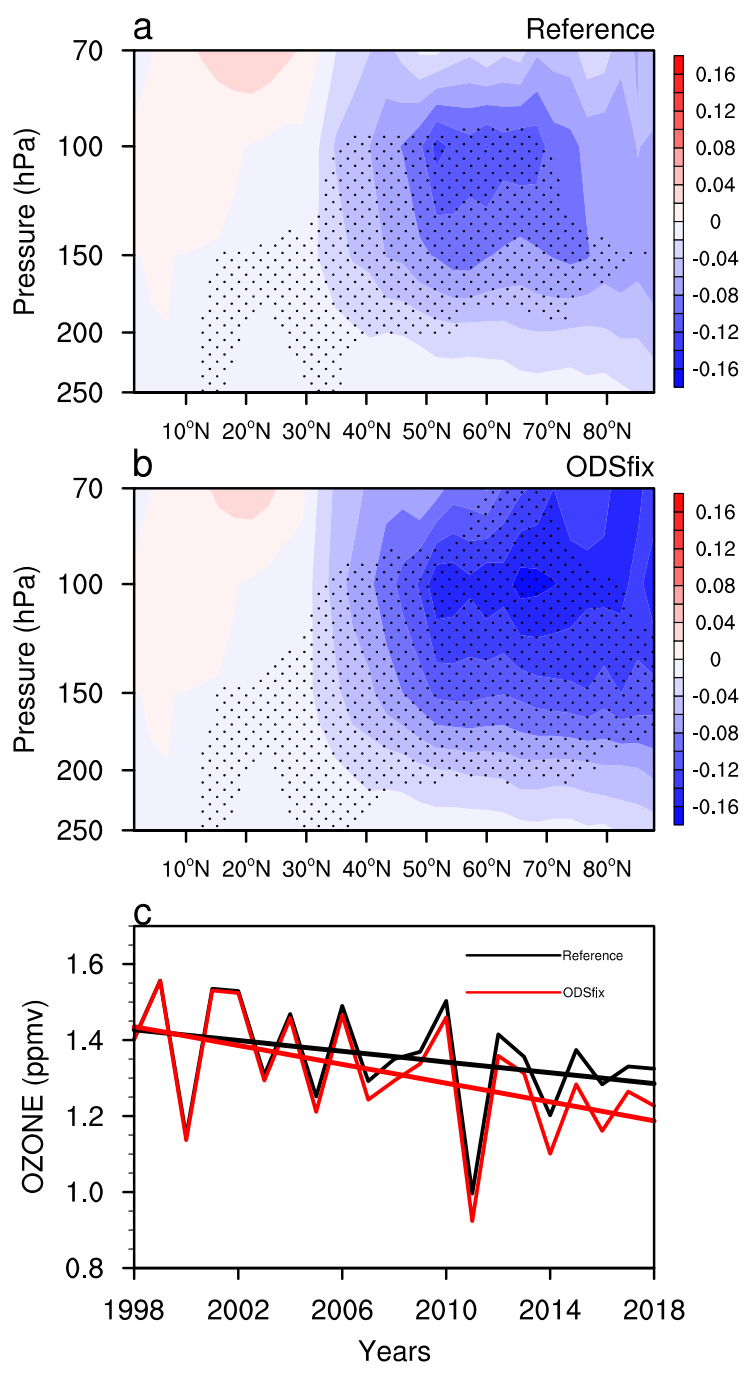

225 Figure 3. Trends (units: ppmv decade ${ }^{-1}$ ) in the zonal mean ozone concentrations in March derived from TOMCAT during 1998-2018, (a) reference run and (b) ODSfix

227 run. The values over the stippled regions are statistically significant at/above the $90 \%$

228 confidence level. (c) Time series of ozone concentrations averaged over $65^{\circ}-90^{\circ} \mathrm{N}$ and

$229 \quad 100-150 \mathrm{hPa}$ from two experiments in March. The black and red straight lines represent 230 the linear trends of ozone concentrations from reference and sensitivity runs, 231 respectively. 


\section{Connections between the Arctic ozone and North Pacific SSTAs}

The factors to affect the stratospheric ozone concentrations include the ODSs through chemical reactions (e.g., Rex et al., 2004) and the SSTs via dynamical processes (e.g., Manzini et al., 2006; García-Herrera et al., 2006; Hu et al., 2014). Previous studies have suggested the delayed impacts of tropical SSTs on the stratosphere (Manzini et al., 2006; García-Herrera et al., 2006) and a significant impact of the North Pacific SSTs on the stratospheric vortex (e.g., Hu et al., 2018). However, the connection between Arctic lower stratospheric ozone and the North Pacific SSTAs is still unclear. Figure 4 shows the SSTAs over the North Pacific in February regressed on $O_{3_{-} A L S}$ during 1980-2018 in March. From Fig. 4a, the SSTAs over the North Pacific exhibit a distinct northeast-southwest-oriented dipole pattern with a band of positive anomalies extending from the coast of California across the Pacific to the western Bering Sea, and a band of negative anomalies extending from the central North Pacific to the coast of Asia, which closely resembles the spatial pattern of the second leading mode of the North Pacific SSTAs (Bond et al., 2003; Ding et al., 2015). We also performed an Empirical Orthogonal Function (EOF) reanalysis of the monthly SSTAs over the North Pacific $\left(100^{\circ} \mathrm{E}-100.5^{\circ} \mathrm{W}, 20.5-65.5^{\circ} \mathrm{N}\right)$ following the method of Bond et al. (2003). The second EOF mode (EOF2) of SSTAs over the North Pacific during 1980-2018 in February (Fig. 4b) accounts for $18.7 \%$ of the total variance. The structure of the EOF2 resembles the pattern of the second leading mode of the North Pacific SSTAs or Victoria mode (Bond et al., 2003; Ding et al., 2015). As expected, the SSTAs over the North

Pacific regressed on $O_{3 \_A L S}$ (Fig. 4a) are very similar to the pattern of the EOF2 of 
SSTAs associated with the Victoria mode.
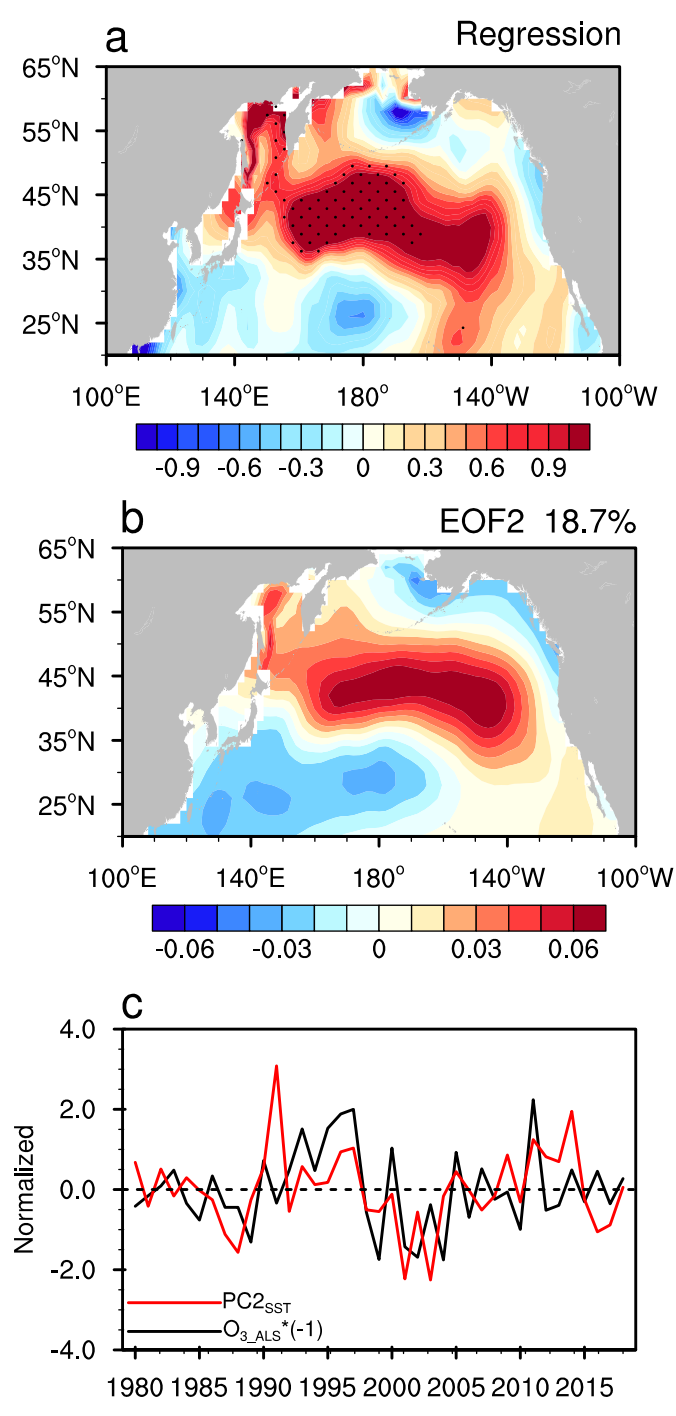

258 Figure 4. (a) Regression of SSTAs (unit: K) over the North Pacific in February on $259 O_{3 \_A L S}$ during 1980-2018 in March. The values over the stippled regions are 260 statistically significant at the $90 \%$ confidence level. (b) EOF2 of SSTA over the North 261 Pacific $\left(20.5-65.5^{\circ} \mathrm{N}, 100^{\circ} \mathrm{E}-100.5^{\circ} \mathrm{W}\right)$ during $1980-2018$ in February. The top-right 262 value is the explained variations of EOF2. Time series of the normalized $P C 2_{S S T}$ (red 263 line) and $O_{3 \_A L S} \times(-1)$ (black line) is shown in (c). 

mode, we also calculated the correlations between the normalized Arctic ozone in

March and the second principal component $\left(P C 2_{S S T}\right)$ of the monthly North Pacific

SSTAs in October-March that leads the $O_{3 \_} A L S$ in March by 5-0 months, shown in

Table 2. The results show that the highest and statistically significant correlation of $P C 2_{S S T}$ with $O_{3 \_A L S}$ in March occurs in February, suggesting that changes in the

North Pacific SSTAs associated with the Victoria mode in February may influence

271 ozone in the Arctic lower stratosphere.

272 Table 2. Correlations of $O_{3_{-} A L S}$ in March with $P C 2_{S S T}$ in October, November,

273 December, January, February, and March that leads $O_{3_{-} A L S}$ in March by $5-0$ months, 274 respectively for the period 1998-2018. Values with asterisks are for those at/above 95\% 275 confidence level.

\begin{tabular}{ccccccc}
\hline Correlations & October & November & December & January & February & March \\
\hline$O_{3 \_A L S}$ & -0.08 & -0.01 & 0.19 & 0.38 & $0.46^{*}$ & 0.35 \\
\hline
\end{tabular}

278 the negative $O_{3 \_} A L S$ is used for purposes of visualization) (Fig. 4c) can clearly be seen, 279 and the correlation coefficient between $P C 2_{S S T}$ and $O_{3_{-} A L S}$ is -0.40 during 1980 2802018 and -0.47 during 1998-2018, respectively, with both values statistically 281 significant at/above the $95 \%$ confidence level. Note that the correlation coefficient 282 between these two indices is only -0.27 during 1980-1997, which is insignificant at the $28390 \%$ confidence level. Similar results can be seen in TOMCAT data (figure not shown). 
This implies that there is an out-of-phase relationship between ozone in the Arctic lower stratosphere and North Pacific SSTAs associated with the Victoria mode, but that this out-of-phase relationship is much stronger during 1998-2018. The interannual correlation between ozone in the Arctic lower stratosphere and North Pacific SSTAs suggests that the decreasing Arctic lower stratospheric ozone trends during 1998-2018 (Fig. 1) are connected to the trends in the North Pacific SSTAs associated with the Victoria mode. The linear trend in $P C 2_{S S T}$ during $1998-2018$ in February is consistent with the trend in $O_{3 \_A L S} \times(-1)$ during 1998-2018 in March (Fig. 4c).

\section{Dynamic mechanisms}

We will now provide evidence for a causal mechanism linking the SSTAs over the North Pacific associated with the Victoria mode to the concentrations of ozone in the Arctic lower stratosphere. Previous studies have shown that the variability of the ozone in the upper stratosphere is dominated by chemical processes, while ozone in the lower stratosphere is strongly affected by dynamical processes (Wargan et al., 2018; Ball et al., 2020; Orbe et al., 2020). It has been shown that the SSTAs over the North Pacific have significant effects on the stratospheric Arctic vortex via dynamical processes (e.g., Hurwitz et al., 2012). Therefore, it is necessary to investigate the possible dynamical mechanisms affecting ozone concentrations in the Arctic lower stratosphere in response to the North Pacific SSTAs in association with the Victoria mode.

Figure 5 shows the anomalies in the geopotential height and horizontal winds at in March from MERRA2 obtained by the regression of the $P C 2_{S S T}$ in February during 1980-2018. In response to the second leading mode of North Pacific SSTAs, there are 
statistically significant positive anomalies in the geopotential height north of $35^{\circ} \mathrm{N}$ in the North Pacific, accompanied by anticyclonic anomalies in the $200 \mathrm{hPa}$ horizontal winds (Fig. 5a). The $P C 2_{S S T}$-related geopotential height over the southwestern North Pacific exhibits negative anomalies accompanied with cyclonic horizontal wind anomalies. The pattern of geopotential height over the North Pacific is consistent with that at $500 \mathrm{hPa}$ (Fig. 5b), also similar to that of SST (Fig. 4b), which indicates a weakened Aleutian low in response to $P C 2_{S S T}$. A previous study has revealed that the warming in the central North Pacific corresponds to a weakened Aleutian low (Hu et al., 2018), consistent with our result here. Tropospheric teleconnection patterns, such as the Western Pacific (WP) and Pacific-North American (PNA) patterns, can be characterized by a deep Aleutian low (Wallance \& Gutzler, 1981). The correlation coefficients between the $P C 2_{S S T}$ and WP, PNA teleconnection patterns at $200 \mathrm{hPa}$ following the definitions in Wallace and Gutzler (1981) are 0.43 and -0.37 , respectively, both at/above the $95 \%$ confidence level. This implies a strengthened WP teleconnection pattern and a weakened PNA teleconnection pattern in response to the positive Victoria mode. 
(a) $200 \mathrm{hPa}$

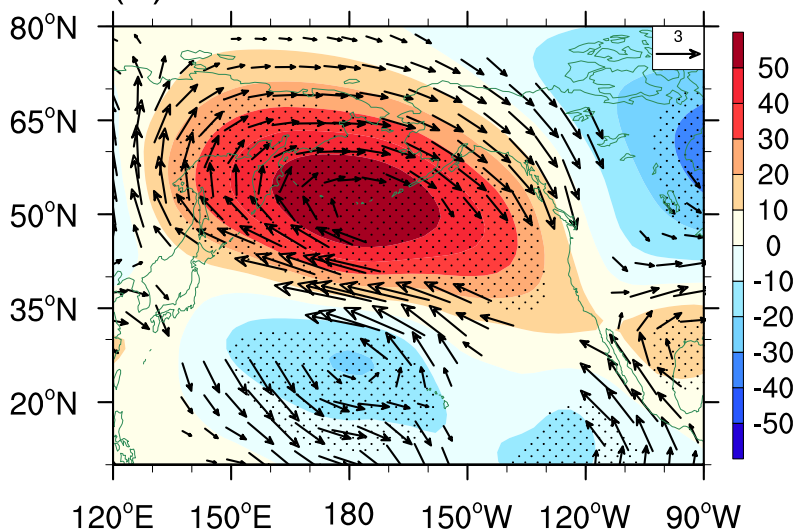

(b) $500 \mathrm{hPa}$

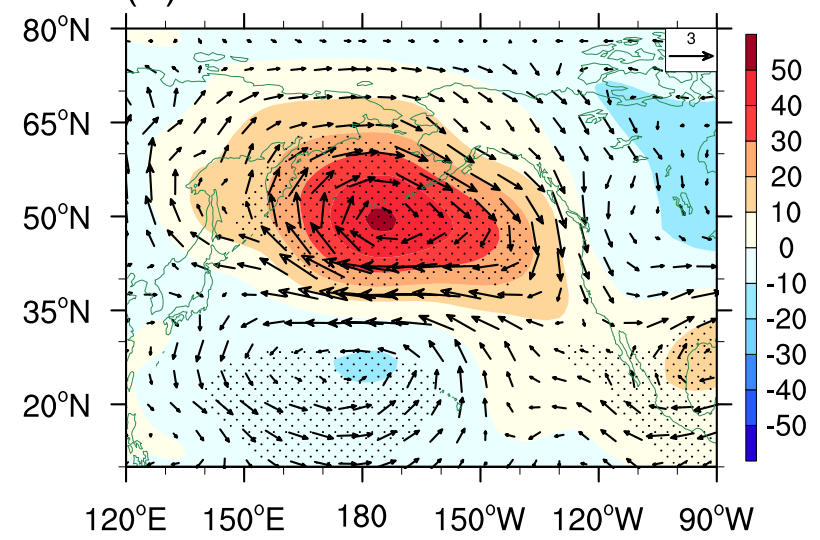

323 Figure 5. Anomalies in the geopotential height (shading) and horizontal winds (vectors,

324 only values above $0.5 \mathrm{~m} \mathrm{~s}^{-1}$ are shown) at (a) $200 \mathrm{hPa}$ and (b) $500 \mathrm{hPa}$ in March obtained by the regression of the $P C 2_{S S T}$ in February during 1980-2018. The values over the stippled regions are statistically significant at the $90 \%$ confidence level. PNA patterns, may affect the wave activity in the stratosphere (Hu et al., 2018).

329 Therefore, the longitudinal and vertical structure of the wavenumber-1 and -2 components of geopotential height averaged over $45^{\circ} \mathrm{N}-75^{\circ} \mathrm{N}$ in response to $P C 2_{S S T}$

331 is shown in Figs. 6a-b. The positive (negative) anomalies in the zonal wavenumber-1

332 component of geopotential height are co-located with its negative (positive) 333 climatologies (Fig. 6b), suggesting a weakened wavenumber-1 planetary wave in 
response to the North Pacific SSTAs. However, anomalies in the wavenumber-2 component of geopotential height are in-phase with its climatologies (Fig. 6b), implying a strengthened wavenumber-2 planetary wave in response to the positive

337 Victoria mode phases. The details of the out-of-phase between the anomalies and 338 climatologies in the wavenumber-1 and -2 components of geopotential height can 339 clearly be seen in Figs. 6c-d, which gives the responses of wavenumber-1 and -2 340 components of geopotential height at $200 \mathrm{hPa}$ to $P C 2_{S S T}$, respectively. This suggests 341 that the weakened WP and strengthened PNA pattern in response to the positive 342 Victoria mode phases are consistent with the weakened wavenumber- 1 component in 343 the wave activity over the upper troposphere and lower stratosphere, which plays the 344 dominant role in the weakened wave flux in the stratosphere in response to the Victoria 345 mode. But the strengthening of the wavenumber-2 components associated with the 346 Victoria mode counteract the weakening of wavenumber-1 to some extent. 
(a) Wavenumber-1

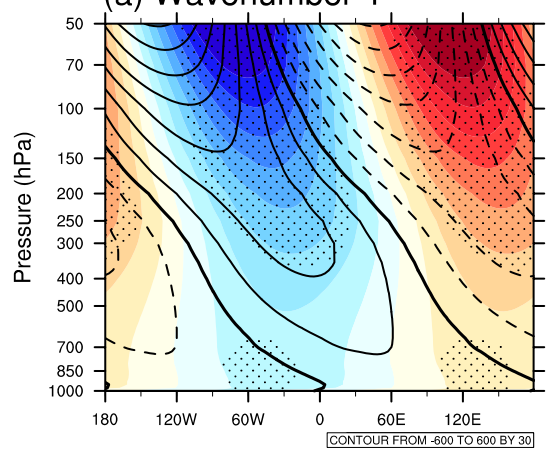

(b) Wavenumber-2

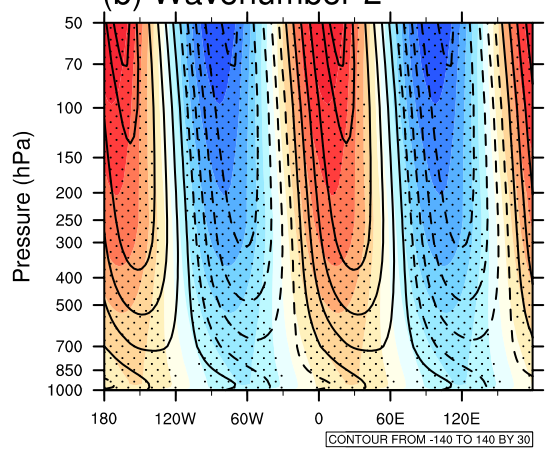

(c)

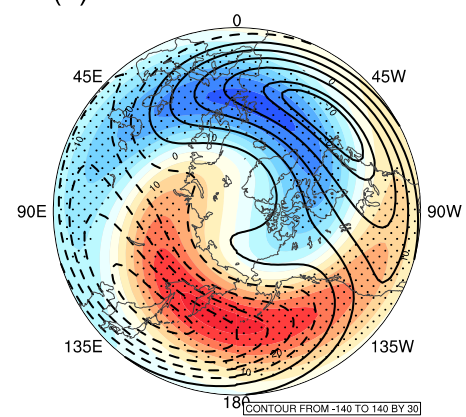

(d)

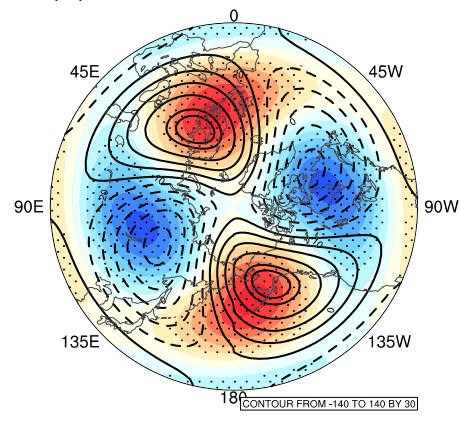

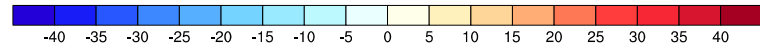

Figure 6. Anomalies (shading) in the (a, c) wavenumber-1 and (b, d) wavenumber-2 components of geopotential height averaged over $45^{\circ} \mathrm{N}-75^{\circ} \mathrm{N}$ (left panels) and at 200

$\mathrm{hPa}$ (right panels) in March regressed on $P C 2_{S S T}$ during 1980-2018. The line contours in represent the climatological mean of wavenumber-1 and -2 components of geopotential height (a, b) averaged over $45^{\circ} \mathrm{N}-75^{\circ} \mathrm{N}$ and (c, d) at $200 \mathrm{hPa}$, respectively. The values over the stippled regions are statistically significant at the $90 \%$ confidence 354 level.

The quasi-geostrophic Eliassen-Palm (EP) flux (Edmon et al., 1980) is used to 356 diagnose the strength and propagation of planetary waves. In response to $P C 2_{S S T}$, there are weakened upward planetary wavenumber-1 waves in the lower stratosphere over the Arctic region (Fig. 7a), with slightly strengthened meridional propagation at mid-latitude in the upper troposphere. However, the planetary wavenumber- 2 waves 

stratosphere with weakened equatorward propagation at mid-latitude in the upper troposphere (Fig. 7b). The weakened wavenumber-1 upward propagation and

363 strengthened wavenumber-2 upward propagation (Fig. 7) are in accord with the 364 weakened wavenumber-1 component but strengthened wavenumber- 2 component in 365 the wave activity over the upper troposphere and lower stratosphere shown in Fig. 6.

366 Note that the weakened upward planetary wvenumber-1 wave propagation is 367 accompanied with positive zonal wind anomalies over the Arctic and negative 368 anomalies at mid-latitudes. This indicates that the subtropical westerly jet weakens in 369 response to the positive $P C 2_{S S T}$ phases, which may not favor the planetary wave 370 upward propagation according to the wave-mean flow interaction theory (Andrews et al., 1987).

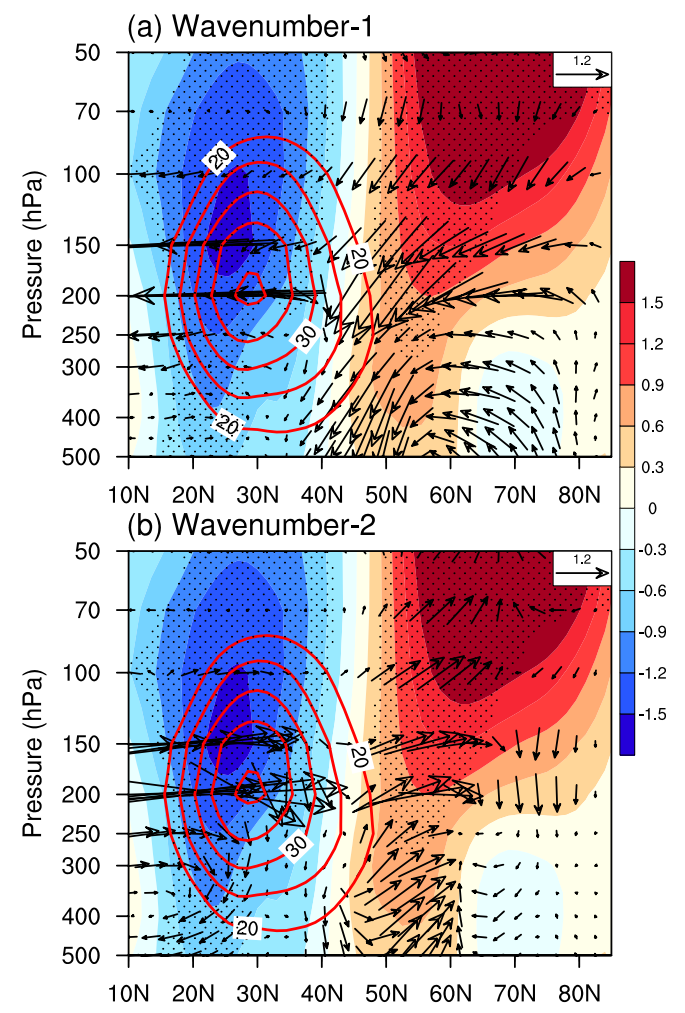

373 Figure 7. Anomalies in the zonal winds (shading, $\mathrm{m} \mathrm{s}^{-1}$ ) and (a) wavenumber-1 and (b) 
wavenumber-2 components of EP flux (arrows with units of $10^{4} \mathrm{~kg} \mathrm{~s}^{-2}$ for vertical vectors and $10^{6} \mathrm{~kg} \mathrm{~s}^{-2}$ for horizontal vectors over $50-200 \mathrm{hPa}$, and $5 \times 10^{4} \mathrm{~kg} \mathrm{~s}^{-2}$ for vertical vectors and $5 \times 10^{6} \mathrm{~kg} \mathrm{~s}^{-2}$ for horizontal vectors over $250-500 \mathrm{hPa}$, respectively) in March regressed on $P C 2_{S S T}$ in February during 1980-2018. The contours represent the climatological mean of zonal winds (only values above $20 \mathrm{~m} \mathrm{~s}^{-1}$ are shown), respectively. The values over the stippled regions are statistically significant at the $90 \%$ confidence level.

Changes in the planetary waves in the lower stratosphere may lead to an anomalous BDC (Hu et al., 2014), which could modulate concentrations of ozone in the stratosphere (Hu et al., 2015). The anomalies of ozone in the Arctic lower stratosphere caused by the BDC and eddy transports can be examined according to the Transformed Eulerian-Mean formulation of the zonal-mean ozone tracer continuity equation (Garcia \& Solomon, 1983) (more details in the Section 2.3). Figure 8 shows the anomalies in the March ozone produced by the BDC and eddy regressed on $P C 2_{S S T}$ in February during 1980-2018. In the Arctic lower stratosphere there are positive ozone anomalies caused by changes in the meridional BDC (Fig. 8a) and negative anomalies caused by changes in the vertical BDC (Fig. 8b), accompanied with the insignificant response of ozone to the eddy transport (Fig. 8c). This implies that the ozone anomalies in the Arctic lower stratosphere in response to $P C 2_{S S T}$ are mainly caused by vertical transport of the BDC, and not by the eddy transport. However, the eddy transports in response to $P C 2_{S S T}$ can result in negative ozone anomalies at mid-latitudes in the lower stratosphere. 

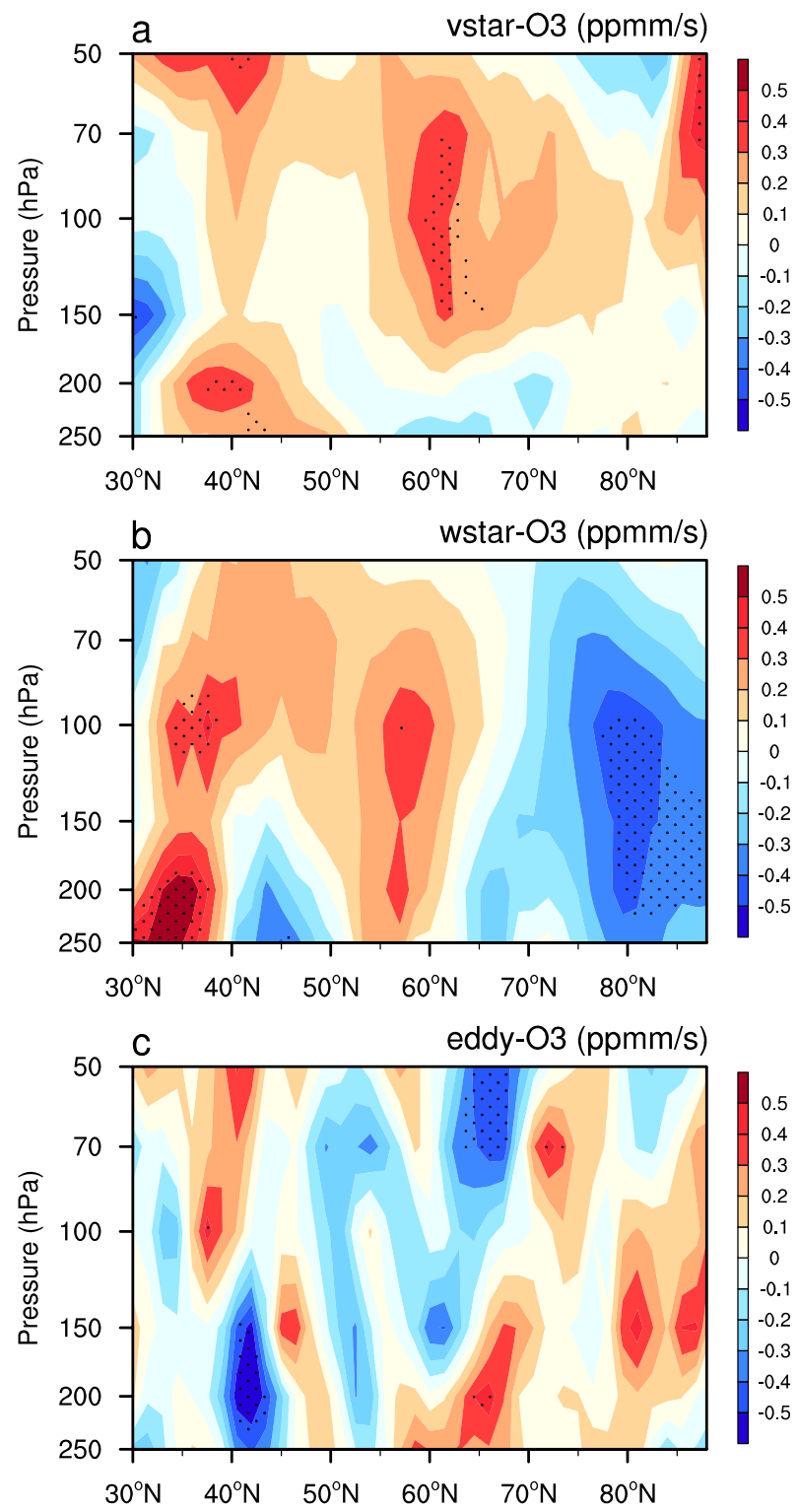

Figure 8. Anomalies in the March ozone (a) $v^{*}$-produced, (b) $w^{*}$-produced, and (c) eddy transported regressed on $P C 2_{S S T}$ in February during 1980-2018. The values over

399 the stippled regions are statistically significant at and above the $90 \%$ confidence level.

As the BDC is closely related to planetary waves in the stratosphere (Butchart et $P C 2_{S S T}$ because of the weakened upward propagation of planetary wave in response to the North Pacific SSTAs. Figure 9 further shows the anomalies in the March $w^{*}$ 
regressed on $P C 2_{S S T}$ in February during 1980-2018. As expected, there are weakened anomalies in the BDC downwelling velocity compared to its climatology in response to the warmed North Pacific SSTAs, which implies a weakened BDC. The weakened BDC downwelling velocity may result in negative ozone anomalies in the Arctic lower stratosphere via the weakening of transport from the ozone-rich middle stratosphere to the ozone-poor lower stratosphere, consistent with Figure 8.
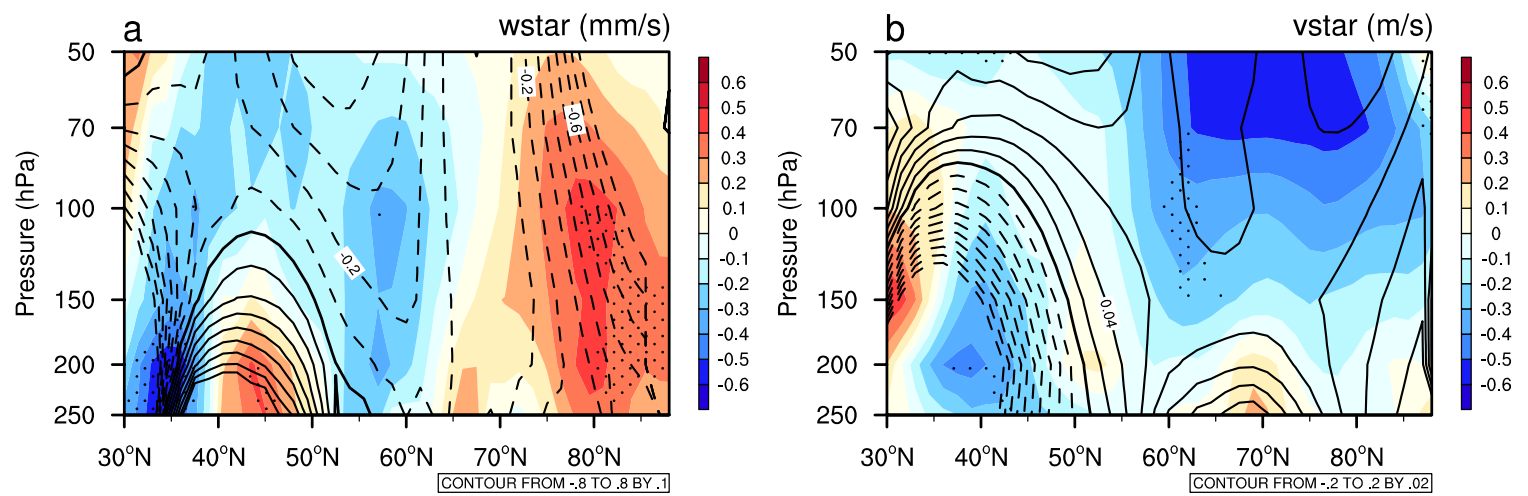

Figure 9. Anomalies in the March $w^{*}$ regressed on $P C 2_{S S T}$ in February during 1980-2018. The dashed and solid contours represent the negative and positive climatological mean of $w^{*}$ in March, respectively. The values over the stippled regions are statistically significant at and above the $90 \%$ confidence level.

Changes in the BDC and eddy transport, the temperatures in the Arctic stratosphere can be also controlled by the anomalous planetary wave activity associated with the North Pacific SSTs. Figure 10 shows the anomalies in temperature and zonal winds in March regressed on $P C 2_{S S T}$ in February during 1980-2018. There are cooling anomalies in the temperature of the lower stratosphere over the Arctic (Fig. 10a), accompanied with strengthened anomalies in the zonal winds (Fig. 10b). These anomalies are in accord with the decreased ozone anomalies. The stronger and more 
422

423

424

425

426

427

428

429

430

431

432

434

variable wave driving can affect the ozone concentrations by both ozone transport (dynamical resupply) and chemical depletion (e.g., Strahan et al., 2016), i.e., stronger (weaker) wave driving is closely associated with increased (decreased) ozone by dynamical resupply and increased (decreased) ozone by reducing (increasing) chemical loss. In addition to the ozone decrease caused by the weakened BDC in response to the Victoria mode (Fig. 9), the cooler Arctic stratosphere (Fig. 10) can increase polar stratospheric cloud occurrence, on whose surface the chlorine-activating heterogeneous reactions occur, further reducing the ozone (Solomon et al., 1994; Chipperfield et al., 1999; Daniel et al., 1999). If the temperatures are low enough and active chlorine is present during the boreal spring, particularly following cold winters, such as 1997 and 2011 (Chipperfield, 2015), photochemical ozone loss may depress the temperature, which in turn enhances the chemical reactions and leads to more ozone loss (Manney et al., 2011).

(a) $\mathrm{T}$

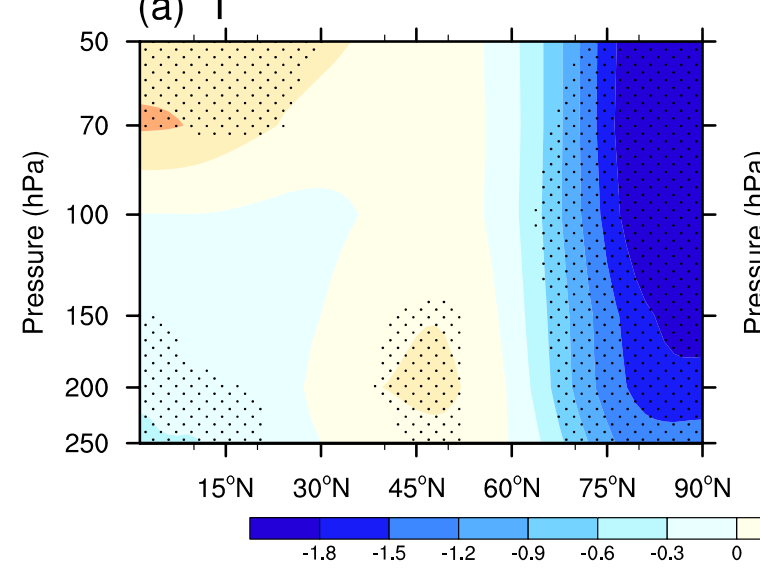

(b) $\mathrm{U}$

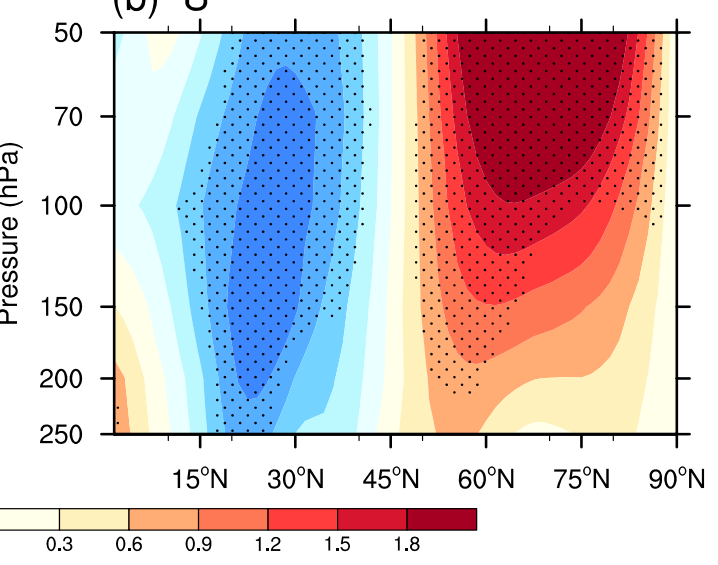

Figure 10. Anomalies in (a) temperature and (b) zonal winds in March obtained by the regression on the $P C 2_{S S T}$ in February during 1980-2018. The values over the stippled regions are statistically significant at the $90 \%$ confidence level. 


\section{Conclusions and discussion}

Using meteorological reanalysis, several observational datasets and a chemical transport model, trends in the concentrations of ozone in the stratosphere over the Arctic and its links to the North Pacific SSTs are examined in this study. Our results show a decreasing trend in the concentrations of ozone in March of $-0.12 \pm 0.07$ ppmv decade ${ }^{-}$

${ }^{1}$ from MERRA2 and $-0.09 \pm 0.07$ ppmv decade ${ }^{-1}$ from TOMCAT after 1998 , in the period following the turnaround in the atmospheric ODS levels.

Further analysis suggested that the SSTAs over the North Pacific associated with the second leading mode in February appear to have large impacts on ozone in the Arctic lower stratosphere in March. Ozone concentrations decrease with the North Pacific SSTAs associated with the warm phases of the Victoria mode, and increase with the North Pacific SSTAs associated with its cold phases. The decrease in ozone over the lower stratospheric Arctic during 1998-2018 is consistent with an increase in the PC2 of the North Pacific SSTAs. The Victoria-mode-related SSTAs tend to result in a weakened Aleutian low accompanied by a strengthened WP pattern and a weakened PNA pattern, which impede the upward propagation of planetary wavenumber-1 waves into the subpolar lower stratosphere. In response to the Victoria mode, the BDC is weakened via weakening the wave propagation, which results in negative ozone anomalies in the lower stratosphere over the Arctic via the weakening of transport from the ozone-rich region in the middle stratosphere to the ozone-poor region in the lower stratosphere. Besides these dynamical processes, the cooler and stronger Arctic stratosphere in response to the North Pacific SSTAs related to the Victoria mode may 
461

462

also affect the ozone concentrations through chemical depletion, which needs further investigation.

Recall that the trends in the ozone at tropics and midlatitudes in the $\mathrm{NH}$ and the potential mechanism are under wide debate (e.g., Ball et al. 2018, 2019; Wargan et al., 2018; Chipperfield et al., 2018b; Orbe et al., 2020). Wargan et al. (2018) provided evidence for a dynamical origin of the observed decreased trend corroborated the results of Ball et al. (2018). Chipperfield et al. (2018b) argued that these trends resulted from natural variability. That met with a response from Ball et al. (2019) who demonstrated robustness of the trends through 2018. Orbe et al. (2020) demonstrated that the trends in ozone in the lower stratosphere in the $\mathrm{NH}$ midlatitudes result from trends in the residual circulation. In this paper, we link the polar ozone in the stratosphere to the BDC. Furthermore, Ball et al. (2020) suggests changes in mixing as a mechanism underpinning these trends, consistent with Wargan et al (2018), and points to an apparent inability of free-running models to reproduce the observed the lowerstratospheric ozone behavior. The latter point is also elaborated on extensively by Dietmüller et al. (2021). This present work explored the trends in the ozone over the Arctic in the stratosphere and uniquely linked the recent ozone depletion in the Arctic stratosphere to the North Pacific SSTs, which might provide another important element to the debate.

\section{Acknowledgements}

We thank Professor Martyn Chipperfield for useful comments and suggestions. We are grateful to the groups and agencies for providing the datasets used in this study, including the Merra2 

GOZCARDS (https://disc.gsfc.nasa.gov/datasets/GozSmlpO3_V1), SBUV (https://disc.

485 gsfc.nasa.gov/datasets/SBUV2N09L3zm_V1), SWOOSH (http:/www.esrl.noaa.gov/csd/groups/ 486 csd8/swoosh/), MLS (https://disc.gsfc.nasa.gov/datasets), and ERSST V5 (https://www.esrl. 487 noaa.gov/psd/data/gridded/data.noaa.ersst.v5.html). This work was supported by the National Key 488 R\&D Program of China (2019YFC1510201) and the National Natural Science Foundation of China 489 (41805031). 
490

491

492

493

494

495

496

497

498

499

500

501

502

503

504

505

506

507

508

509

510

511

512

513

514

\section{References}

Andrews, D. G., Holton, J. R. \& Leovy, C. B. Middle Atmosphere Dynamics. Academic Press Inc., 489 pp (1987).

Ball, W. T. et al. Evidence for a continuous decline in lower stratospheric ozone offsetting ozone layer recovery. Atmos. Chem. Phys., 18, 1379-1394 (2018).

Ball, W. T., Alsing, J., Staehelin, J., Davis, S. M., Froidevaux, L. \& Peter, T. Stratospheric ozone trends for 1985-2018: sensitivity to recent large variability, Atmos. Chem. Phys., 19: 12731-12748 (2019).

Ball, W. T., Chiodo, G., Abalos, M., Alsing, J. \& Stenke, A. Inconsistencies between chemistry-climate models and observed lower stratospheric ozone trends since 1998. Atmos. Chem. Phys., 20: 9737-9752 (2020).

Bednarz, E. M., Maycock, A. C., Abraham, N. L., Braesicke, P., Dessens, O. \& Pyle, J. A. Future Arctic ozone recovery: the importance of chemistry and dynamics. Atmos. Chem. Phys., 16, 12159-12176 (2016).

Bhartia, P. K. et al. Solar Backscatter UV (SBUV) total ozone and profile algorithm. Atmos. Meas. Tech., 6, 2533-2548 (2013).

Bond, N. A., Overland, J. E., Spillane, M. \& Stabeno, P. Recent shifts in the state of the North Pacific. Geophys. Res. Lett., 30, 2183 (2003).

Bourassa, A. E. et al. Trends in stratospheric ozone derived from merged Odin-OSIRIS and SAGE II satellite observations. Atmos. Chem. Phys., 14, 6983-6994 (2014).

Butchart, N. The Brewer-Dobson circulation. Rev. Geophys., 52: 157-184 (2014).

Calvo, N., Polvani, L. M. \& Solomon, S. On the surface impact of Arctic stratospheric ozone extremes. Environ. Res. Lett., 10, 094003 (2015).

Chipperfield, M. P. \& Jones, R. L. Relative influences of atmospheric chemistry and transport on Arctic ozone trends. Nature, 400, 551-554 (1999). 
Chipperfield, M. P. New version of the TOMCAT/SLIMCAT off-Line chemical transport model: Intercomparison of stratospheric tracer experiments. Quart. J. Roy. Meteor. Soc., 132, 1179-1203 (2006).

Chipperfield, M. P., Dhomse, S. S., Feng, W., McKenzie, R. L., Velders, G. J. M. \& Pyle, J. A. Quantifying the ozone and ultraviolet benefits already achieved by the Montreal Protocol. Nat Commun., 6, 7233 (2015).

Chipperfield, M. P. et al. Quantifying the ozone and ultraviolet benefits already achieved by the Montreal Protocol. Nat. Commun., 6, 7233 (2018a).

Chipperfield, M. P. et al. On the cause of recent variations in lower stratospheric ozone. Geophys. Res. Lett., 45 (2018b).

Cohen, Y. et al. Climatology and long-term evolution of ozone and carbon monoxide in the upper troposphere-lower stratosphere (UTLS) at northern midlatitudes, as seen by IAGOS from 1995 to 2013. Atmos. Chem. Phys., 18, 5415-53 (2018).

Dameris, M., Loyola, D. G., Nützel, M., Coldewey-Egbers, M., Lerot, C., Romahn, F. \& van Roozendael, M. Record low ozone values over the Arctic in boreal spring 2020. Atmos. Chem. Phys., 21, 617-633 (2021).

Daniel, J. S., Solomon, S., Portmann, R. W. \& Garcia R. R. Stratospheric ozone destruction: The importance of bromine relative to chlorine. J. Geophys. Res. Atmos., 104, 23, 871-23,880 (1999).

Davis, S. M. et al. The Stratospheric Water and Ozone Satellite Homogenized (SWOOSH) database: a long-term database for climate studies. Earth. Syst. Sci. Data., 8, 461-490 (2016).

Dietmüller, S., Garny, H., Eichinger, R. \& Ball, W. T. Analysis of recent lower stratospheric ozone trends in chemistry climate models. Atmos. Chem. Phys. Discuss., https://doi.org/10.5194/acp-2020-947, in review, (2021). 
Dunkerton, T. On the Mean Meridional Mass Motions of the Stratosphere and Mesosphere. J. Atmos. Sci., 35, 2325-2333 (1978).

Ding, R., Li, J., Tseng, Y. H., Sun, C. \& Guo, Y. The Victoria mode in the North Pacific linking extratropical sea level pressure variations to ENSO. J. Geophys. Res. 120, 27-45 (2015).

Edmon, H. J., Hoskins, B. J. \& McIntyre, M. E. Eliassen-Palm cross-sections for the troposphere, J. Atmos. Sci., 37, 2600-2616 (1980).

Eyring, V. et al. Multimodel projections of stratospheric ozone in the 21 st century. $J$. Geophys. Res. Atmos., 112, D16303 (2007).

Froidevaux, L. et al. Global Ozone Chemistry And Related Datasets for the Stratosphere (GOZCARDS): methodology and sample results with a focus on $\mathrm{HCl}, \mathrm{H} 2 \mathrm{O}$, and O3. Atmos. Chem. Phys., 15, 10471-10507 (2015).

Garcia, R. R. \& Solomon, S. A Numerical Model of the Zonally Averaged Dynamical and Chemical Structure of the Middle Atmosphere. J. Geophys. Res., 88, 13791400, (1983).

García-Herrera, R., Calvo, N., Garcia, R. R. \& Giorgetta, M. A. Propagation of ENSO temperature signals into the middle atmosphere: a comparison of two general circulation models and ERA-40 reanalysis data. J. Geophys. Res. 111, (2006).

Gelaro, R. et al. The Modern-Era Retrospective Analysis for Research and Applications, Version 2 (MERRA-2). J. Climate (2017) 30: 5419-5454.

Grooss, J. U. et al. On the discrepancy of $\mathrm{HCl}$ processing in the core of the wintertime polar vortices. Atmos. Chem. Phys., 18, 8647-8666 (2018).

Huang, B. et al. Extended Reconstructed Sea Surface Temperature, Version 5 (ERSSTv5): Upgrades, Validations, and Intercomparisons. J. Clim., 30, 81798205 (2017). 
Hu, Y. \& Tung, K. K. Possible ozone-induced long-term changes in planetary wave activity in late winter. J. Clim., 16, 3027-3038 (2003).

Hu, D., Tian, W., Xie, F., Shu, J. \& Dhomse, S. Effects of meridional sea surface temperature changes on stratospheric temperature and circulation. Adv. Atmos. Sci., 31, 888-900 (2014).

Hu, D., Tian, W., Xie, F., Wang, C. \& Zhang, J. Impacts of stratospheric ozone depletion and recovery on wave propagation in the boreal winter stratosphere. J. Geophys. Res. Atmos., 120, 8299-8317 (2015).

Hu, D., Guan, Z., Tian, W. \& Ren, R. Recent strengthening of the stratospheric Arctic vortex response to warming in the central North Pacific. Nat Commun., 9, 1697 (2018).

Hurwitz, M. M., Newman, P. A. \& Garfinkel, C. I. On the influence of North Pacific sea surface temperature on the Arctic winter climate. J. Geophys. Res. Atmos., 117, D19 (2012).

Inness, A. et al. Exceptionally low Arctic stratospheric ozone in spring 2020 as seen in the CAMS reanalysis. J. Geophys. Res., 125, e2020JD033563 (2020).

Ivy, D. J., Solomon, S., Calvo, N. \& Thompson, D. W. J. Observed connections of Arctic stratospheric ozone extremes to Northern Hemisphere surface climate. Environ. Res. Lett., 12, 024004 (2017).

Kang, S. M., Polvani, L. M., Fyfe, J. C. \& Sigmond, M. Impact of polar ozone depletion on subtropical precipitation. Science, 332, 951-954 (2011).

Kramarova, N. A. et al. Validation of ozone monthly zonal mean profiles obtained from the version 8.6 Solar Backscatter Ultraviolet algorithm. Atmos. Chem. Phys., 13, 6887-6905 (2013).

Lawrence, Z. D., Perlwitz, J., Butler, A. H., Manney, G. L., Newman, P. A., Lee, S. H. 
\& Nash, E. R. The remarkably strong Arctic stratospheric polar vortex of winter 2020: Links to record breaking Arctic Oscillation and ozone loss. J. Geophys. Res., 125, e2020JD033271 (2020).

Manney, G. L. et al. Polar processing in a split vortex: Arctic ozone loss in early winter 2012/2013. Atmos. Chem. Phys., 15, 5381-403 (2015).

Manney, G. L. et al. Unprecedented Arctic ozone loss in 2011. Nature, 478, 469-475 (2011).

Manney, G.L. et al. Record-low Arctic stratospheric ozone in 2020: MLS observations of chemical processes and comparisons with previous extreme winters. Geophys. Res. Lett., 47, e2020GL089063 (2020).

Manzini, E., Giorgetta, M. A., Esch, M., Kornblueh, L. \& Roeckner, E. The influence of sea surface temperatures on the northern winter stratosphere: ensemble simulations with the MAECHAM5 model. J. Climate, 19, 3863-3881 (2006).

Orbe, C., Wargan, K., Pawson, S., \& Oman, L. D. Mechanisms linked to recent ozone decreases in the Northern Hemisphere lower stratosphere. J. Geophys Res., 125, e2019JD031631 (2020).

Polvani, L. M., Waugh, D. W., Correa, G. J. P. \& Son, S. W. Stratospheric Ozone Depletion: The Main Driver of Twentieth-Century Atmospheric Circulation Changes in the Southern Hemisphere. J. Climate, 24, 795-812 (2011).

Ramaswamy, V. et al. Radiative forcing of climate. Clim. Change., 349 (2001).

Rex, M. et al. Arctic ozone loss and climate change. Geophys. Res. Lett., 31, (2004).

Schwartz, M., Froidevaux, L., Livesey, N., Read, W. \& Fuller, R. MLS/Aura Level 3 Monthly Binned Ozone (O3) Mixing Ratio on Assorted Grids V005, Greenbelt, MD, USA, Goddard Earth Sciences Data and Information Services Center (GES DISC), Accessed: [Data Access Date], 10.5067/Aura/MLS/DATA/3546, (2021). 
Solomon, S., Garcia, R. R. \& Ravishankara A. R. On the role of iodine in ozoned epletion. J. Geophys Res., 99, 20,491-20,499 (1994).

Son, S. W. et al. Impact of stratospheric ozone on Southern Hemisphere circulation change: A multimodel assessment. J. Geophys. Res. Atmos, 115 (2010).

Steinbrecht, W. et al. An update on ozone profile trends for the period 2000 to 2016. Atmos. Chem. Phys., 17, 10675-90 (2017).

Strahan, S. E., Douglass, A. R. \& Steenrod, S. D. Chemical and dynamical impacts of stratospheric sudden warmings on Arctic ozone variability. J. Geophys. Res. Atmos., 121, (2016).

Thompson, D. W. J. et al. Signatures of the Antarctic ozone hole in Southern Hemisphere surface climate change. Nat.Geosci., 4, 741-749 (2011).

Tilmes, S., Müller, R., Grooß, J.-U. \& Russell, J. M. Ozone loss and chlorine activation in the Arctic winters 1991-2003 derived with the tracer-tracer correlations. Atmos. Chem. Phys., 4, 2181-2213 (2004).

Tummon, F. et al. Intercomparison of vertically resolved merged satellite ozone data sets: interannual variability and long-term trends. Atmos. Chem. Phys., 15, 302143 (2015).

Wallace, J. M. \& Gutzler, D. S. Teleconnections in the geopotential height field during the Northern Hemisphere winter. Mon. Wea. Rev., 109, 784-812 (1981).

Wargan, K. et al. Recent decline in extratropical lower stratospheric ozone attributed to circulation changes. Geophys. Res. Lett., 45, 5166-5176 (2018).

Weatherhead, E. C. \& Andersen, S. B. The search for signs of recovery of the ozone layer. Nature, 441, 39-45 (2006).

Witze, A. Rare ozone hole opens over Arctic_-and it's big. Nature (2020) 580:18.

Wohltmann, I., P. et al. Near-complete local reduction of Arctic stratospheric ozone by 

(2020).

642 WMO. Scientific assessment of ozone depletion: 2006: World Meteorological 643 Organisation, Global Ozone Research and Monitoring Project-Report, 50, 572 $644 \quad$ (2007).

645 WMO. Scientific Assessment of Ozone Depletion. Global ozone research and 646 monitoring project (Report No. 58, p. 588). Geneva, Switzerland. Geneva, $647 \quad$ Switzerland (2018). 